\title{
Promoting Data Collection in Pollinator Citizen Science Projects
}

\author{
Elias H. Bloom*† and David W. Crowder*
}

Pollinators provide ecosystem services that are threatened by the loss of wild and managed bees. Citizen scientists can monitor bees to yield useful data that may guide conservation of threatened bee populations. However, the factors that promote data collection in pollinator citizen science projects are largely unknown, inhibiting development of citizen science that promotes pollinator conservation. We used data from two citizen science projects to assess factors that mediated data collection by volunteers who monitored bees in Washington State, USA, from 2015 to 2017. One project monitored bee-plant interactions with photography; the other gave volunteers nest boxes to monitor cavity-nesting bees. Both projects involved educational trainings, although the project methods differed. Volunteers were given post-training questionnaires to assess their motivations for participation and to evaluate if the volunteer's level of educational attainment influenced data collection. Citizen scientists who monitored cavity-nesting bees were more likely than those who monitored plant-bee interactions to submit data. Data collection was independent of educational attainment, and participants in both projects were more likely to volunteer for their own educational reasons rather than to collect data. Our findings suggest that pollinator citizen science projects which use nest boxes to monitor cavity-nesting bees will receive more data submissions, indicating that these projects may be particularly useful for monitoring pollinators. More broadly, our results suggest that researchers must carefully evaluate project methods, and volunteer motivations, prior to offering trainings to increase rates of data collection.

Keywords: data collection; educational attainment; educational courses; pollinator conservation; volunteer motivations; project methods

\section{Introduction}

Wild and managed bees provide essential pollination services to crops and natural ecosystems (Goulson et al. 2015). Because populations of wild and managed bees are globally threatened (Goulson et al. 2015), monitoring is critical to conserving pollinator populations (Ullman et al. 2010; LeBuhn et al. 2016; Roy et al. 2016; Wilson et al. 2017; Pocock et al. 2018). Engaging volunteers in monitoring may help to provide researchers with essential data on the factors mediating pollinator population declines (Kaartinen, Hardwick, and Roslin 2013; Le Féon et al. 2016; Pocock et al. 2018). However, the factors that promote data collection in pollinator citizen science projects are largely unknown (but see van der Wal et al. 2016; Domroese and Johnson 2017; Klienke et al. 2018), contributing to uncertainty in the methods that may be most useful for wild and managed bee pollinator conservation worldwide.

\footnotetext{
* Department of Entomology, Washington State University, Pullman, WA, US

Department of Entomology, Michigan State University, East Lansing, MI, US

Corresponding author: Elias Bloom (bloomel1@msu.edu)
}

Investigations into the motivations of citizen scientists indicate that volunteers engage in projects to assist in data collection (Wright et al. 2015). However, citizen scientists may have diverse motivations including recreation (Dickinson et al. 2012; Lucrezi et al. 2018), education (Sullivan et al. 2009; Bonney et al. 2009; Domroese and Johnson 2017), and environmental concerns (Graham et al. 2014; Lucrezi et al. 2018), and these motivations may depend on the project. While few studies have addressed the motivations of volunteers who engaged in pollinator citizen science projects, one revealed that volunteers engaged in such projects primarily to learn more about pollinators (Domroese and Johnson 2017). This may suggest that volunteers engage in pollinator citizen science for educational reasons rather than to assist with data collection. Often, citizen science projects are developed to enhance education of the volunteer (Bonney et al. 2009; Dickenson et al. 2012; Druschke and Seltzer 2013; Sauermann and Franzoni 2015; Turrini et al. 2018). This goal is then balanced with data collection, creating a project that has educational benefits for volunteers while also enhancing data collection for researchers (Bonney et al. 2009). However, if volunteers engage in pollinator citizen science projects primarily for educational purposes without an intent to engage in data collection, this 
may undercut the data collection goal of the pollinator researcher (Bonney et al. 2009). Addressing this issue of the balance between education and data collection is important for promoting global pollinator research and conservation but has received scant attention.

Project methods also strongly affect rates of data collection by volunteers. Projects that involve complex methodologies, with multiple detail-oriented steps, are less likely to receive data submissions (Birkin and Goulson 2015; Kleinke et al. 2018). Conversely, projects that use easier, simple methods, and allow more flexibility in the data collection protocol, often receive more data (Kelling et al. 2019). Approaches by pollinator researchers to develop methods for data collection by volunteers are varied (Kremen, Ullman, and Thorp 2011; Birkin and Goulson 2015; Potter and LeBuhn 2015; Domroese and Johnson 2017; Kleinke et al. 2018; Mason and Arathi 2019). Many projects use simplified versions of pollinator surveys which pool pollinator species into easily identifiable groups (Kremen, Ullman, and Thorp 2011). These surveys often involve photo documentation of the pollinator, which can allow researchers to verify observations (Ullman et al. 2010). The goal of these projects is to monitor pollinator biodiversity in a given natural or agronomic ecosystem (Kremen, Ullman, and Thorp 2011), and these data collected by volunteers using simplified methods often differ little from researcher-collected data (Kremen, Ullman, and Thorp 2011). Still other projects leverage volunteers to document plant-bee interactions with the goal of monitoring pollination services (Birkin and Goulson 2015; Kleinke et al. 2018). While globally important (Goulson et al. 2015), monitoring pollination services can rely on multiple steps and can be challenging for volunteers (Birkin and Goulson 2015; Kleinke et al. 2018). For example, in one study, $50 \%$ of volunteers were unable to collect data on pollination services with the methods outlined by researchers (Birkin and Goulson 2015). These studies indicate that project methods may strongly affect data collection in pollinator citizen science, although this has rarely been tested directly.

The level of educational attainment (highest level of education) of the citizen scientist also could affect data collection. Data on the level of educational attainment of citizen scientists is not lacking in the literature (Brossard, Lewenstein, and Bonney 2011; Branchini et al. 2015; Domroese and Johnson 2017), although most studies used these data to assess whether volunteers are representative of a broader population (Crall et al. 2013), or to assess recruitment shortcomings (Wright et al. 2015). While citizen scientists often have higher levels of educational attainment than the general population (Domroese and Johnson 2017; Roman et al. 2017), there is scant evidence as to whether the level of educational attainment affects propensity for data collection. Many pollinator citizen science projects leverage volunteers from urban centers that are skewed toward the highly educated (Potter and LeBuhn 2015; Mason and Arathi 2019). However, the vast majority of agricultural land that relies on pollinators is found outside of urban areas (Koh et al. 2016) where the level of educational attainment is lower (USDA 2017). More broadly, only $7 \%$ of the global population has attained a college degree (Barro and Lee 2013), indicating that researchers will likely need to rely on those with lower levels of educational attainment to gather data on wild and managed bee pollinators at the global scale. Thus, it is essential to determine whether the level of educational attainment influences data collection by volunteers.

Here we used two citizen science projects to evaluate the factors promoting data collection by volunteers. The projects focused on monitoring pollinator populations in the Puget Sound Region of Washington State, USA. Our projects were inspired by national and global efforts to address the decline of wild and managed bee pollinators (Pollinator Health Task Force 2015), and were developed by a team of Entomologists at Washington State University, Pullman, WA, USA. The project team trained volunteers in methods commonly accepted by researchers to collect high quality data on pollinators (Kremen, Ullman, and Thorp 2011; Graham et al. 2014) and followed many of the design principles recommended for citizen science projects more generally (Bonney et al. 2009; Phillips et al. 2014). Each project in our study used dramatically different methods, allowing us to determine how different project methods may have mediated rates of data collection by volunteers.

One project involved monitoring plant-bee interactions with observations and photography. This project was inspired by previous studies that used similar methods to monitor pollinator biodiversity in agroecosystems (Kremen, Ullman, and Thorp 2011). The goal of this project was to determine the floral resources that support pollinator populations. Our second project assessed the habitat needs of cavity-nesting bees using artificial nest boxes (Graham et al. 2014). This project documented the nesting habits of wild bee pollinators with the goal of determining the restoration needs for pollinator habitat in the study region. Both projects were extensions of monitoring conducted by the project team in the region (Bloom, Northfield, and Crowder 2019), and our overall goal was to extend our monitoring network by including observations by citizen scientists. Each project included trainings that educated volunteers in the project methods and all volunteers were evaluated with a questionnaire to ascertain their motivations for participating in the project and to determine their level of educational attainment. We used these questionnaires, and records of data submissions, to assess whether volunteer motivations, project methods, and the level of educational attainment affected the propensity for data collection on wild and managed bee pollinators.

\section{Materials and Methods Community partners, project promotion, and training locations}

In 2015, we partnered with two non-profits (Seattle Tilth and 21 Acres) and one government entity (Seattle Parks and Recreation) to conduct our two science projects (the Pollinator Post Project and WildBeeSense Biodiversity Survey). These partners provided classrooms at 10 locations across metropolitan Seattle, Washington, USA (Figure 1). The projects were initiated to enhance data 


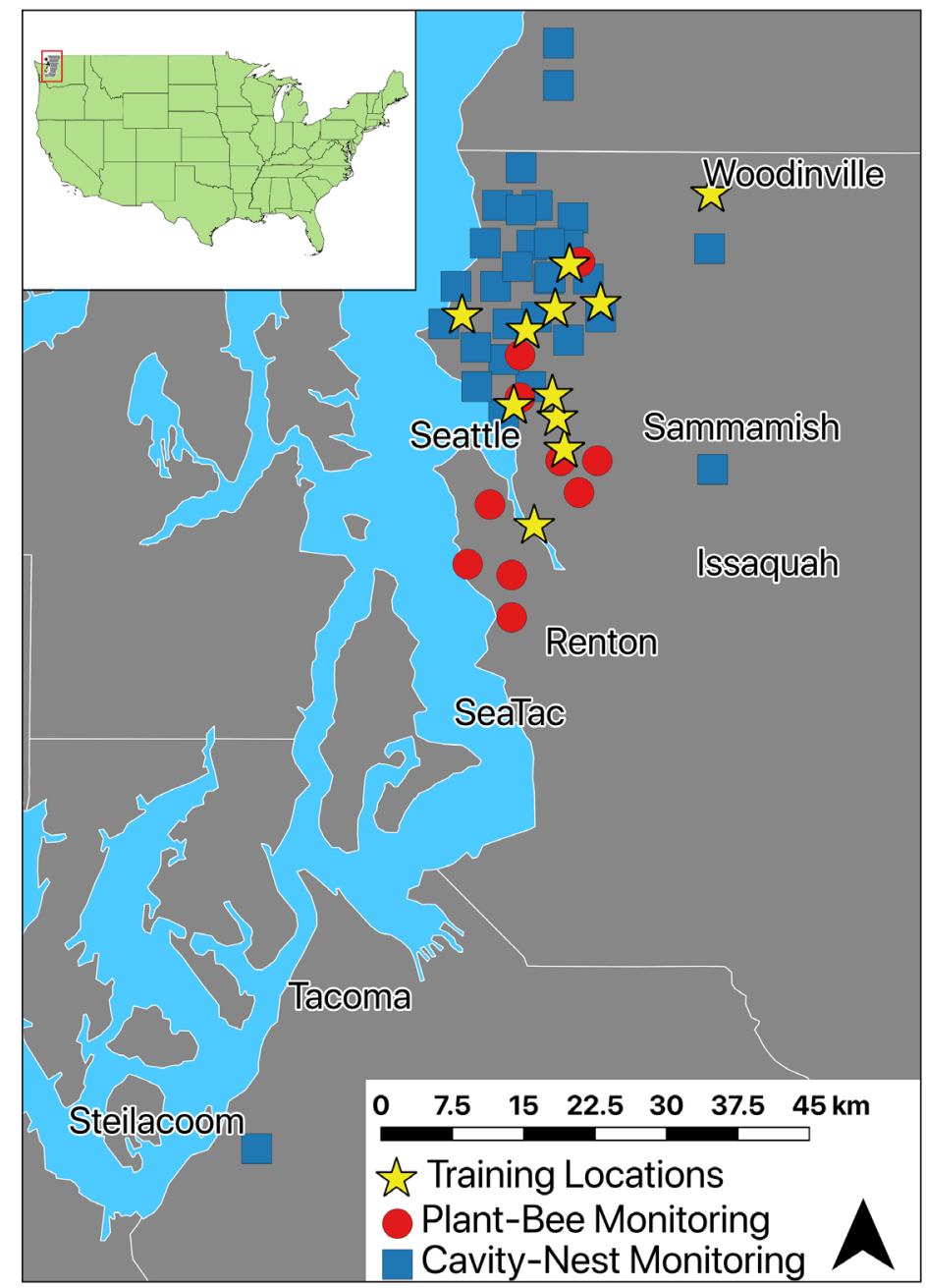

Figure 1: Scope of the study. Shown are training locations (yellow stars), plant-bee network monitoring sites (red dots), and habitat preference evaluation sites (blue squares).

collection on the floral and nesting resources used by pollinator populations in the region, with an overarching goal of extending our research network to include observations made by citizen scientists (Bloom, Northfield, and Crowder 2019). The study systems were urban gardens, which all had high crop diversity and used organic farming practices. Training locations were in close proximity to urban gardens so we could demonstrate data collection techniques. Promotion was preformed through email and fliers, and all volunteers self-selected and registered in advance for each training.

\section{Citizen science trainings}

We produced two citizen science trainings, one training per project. One taught the trainee to identify floral visitors and record plant-bee interactions using photography. The second taught trainees about the habitat needs of bees and gave them artificial nests to monitor wild bee nesting preferences. Trainings were led by the project team, all of whom were trained in pollinator identification and monitoring. Each training was two hours, starting with trainee introductions. Trainees were then given a presentation describing the citizen science project and shown how to use microscopes and handle insect specimens. Trainees were then guided through the microscopic identification of insects relevant to each training. The second half of each training was devoted to discussing data collection techniques and submitting data to our website. Training leaders demonstrated data collection techniques in urban gardens near each training location to provide in-field experience and explained that data gathered by the project would be used to monitor and promote pollinator populations in the region. At the end of each training, training leaders distributed the materials necessary to collect data for each project along with a guidebook (Bloom, Olsson, and Crowder 2017; Bloom et al. 2017).

While these trainings were similar in structure, trainees were required to collect data using different methods. In our training to educate volunteers on monitoring plantbee interactions with photography, trainees were given instructions on the best conditions under which to make observations (weather and time of day), the location from which observations would be suitable for submission to the project (urban gardens), and how to use our data collection form. Each data collection form recorded the name of the observer, date, duration of observation, GPS location, weather, and temperature. After collecting these metadata, the trainee was required to conduct a five-step process. In the first step, the trainee would record whether the observation was of a bee or other floral visitor (wasp, fly, butterfly, beetle, bug, or spider). If the floral visitor was a bee, in the second and third steps the trainee would then 
identify the bee to five morphological groups (honey bee, bumble bee, other large bee, green bee, and small bee) and take a photograph of the bee and the plant (flower, leaf, and leaf attachment to the stem) from which the bee was collecting resources. In the fourth step, the trainee would take extra notes about the observation, and in the fifth step the volunteer would submit these data online at our website. Submitting data online included logging into our website, selecting the correct submission form, copying data from the data form to the webpage, and uploading the photos. Importantly, photographing bees and making detailed observations can be highly challenging (Ullman et al. 2010; Kremen, Ullman, and Thorp 2011), however, this is often the only means to collect high-quality verifiable data on resource use by wild and managed bee pollinators.

Our second project, which evaluated the nesting preferences of wild bees, used a vastly different methodology. Prior to training sessions, we constructed nest boxes to give to trainees (Figure 2). Trainees were instructed on where to install the nest box (in urban gardens) and at what time of year (February and March). Installation of nest boxes before spring was recommended, as many wild bees emerge in the spring and immediately search for nesting sites (Bloom et al. 2017). Trainees were also given a step-in fence post onto which the nest box was attached by the volunteer with plastic zip ties. After installation, we requested that the trainee make observations three times per year in the spring (April-May), summer (June-July), and fall (August-September). Similar to the plant-bee interactions training, trainees were instructed to make observations of nests under specific environmental conditions between 09:00 and 18:00 and given a datasheet that collected the observer name, date, and location of the nest box. The first step in the observation process was to record the nest box number; each nest box was given a unique number so we could track the nest box throughout the course of our project. The trainee was then asked to observe the nest box for $15 \mathrm{~min}$ to determine the frequency of bee visits. The trainee would then count the number of nests that were filled with wild bee nesting materials and take an optional picture of their nest box. These data would then be submitted online at our website. At the end of the growing season (November), we requested that trainees remove the nest box from the step-in fence post and mail us the nest through the United States postal service. These nests were later incubated to determine the nest preference for different wild bee species (data not shown).

\section{Post-training questionnaire}

All trainees were asked to participate in a post-training Likert-scale questionnaire that assessed the trainee's degree of agreement with a set of standardized statements, with the same statements used for both projects. The questionnaire was developed and pre-tested at Washington State University to prevent the use of double-barreled and negative questions, leading items, and confusing language, all of which can bias questionnaire results (Jamieson 2004; Phillips et al. 2014). Our questionnaire used a 5-point scale ranging from "Strongly Disagree" to "Strongly Agree" with "Neither Agree nor Disagree" in the middle. Each level of the scale was assigned a numeric value for coding, starting at one for "Strongly Disagree" and ranging to five for "Strongly Agree." Likertscale questionnaires are a statistically valid psychometric response scale (Phillips et al. 2014) that reliably measures the attitudes and preferences of volunteers (Likert 1932; Jamieson 2004).

The purpose of our questionnaire was to assess the motivations of trainees, evaluate the clarity of expectations for participation in the projects, and examine the trainee's perception of training quality and content. The questionnaire also assessed each trainee's knowledge of wild bee pollinators before and after the training and their reason for attending (i.e., to learn more about wild bees and/or to become part of a citizen science program), and addressed whether trainees intended to submit data on our website (see Table 1 for complete questionnaire statements). Trainees were allotted five minutes to complete the questionnaire, and all responses were anonymous.

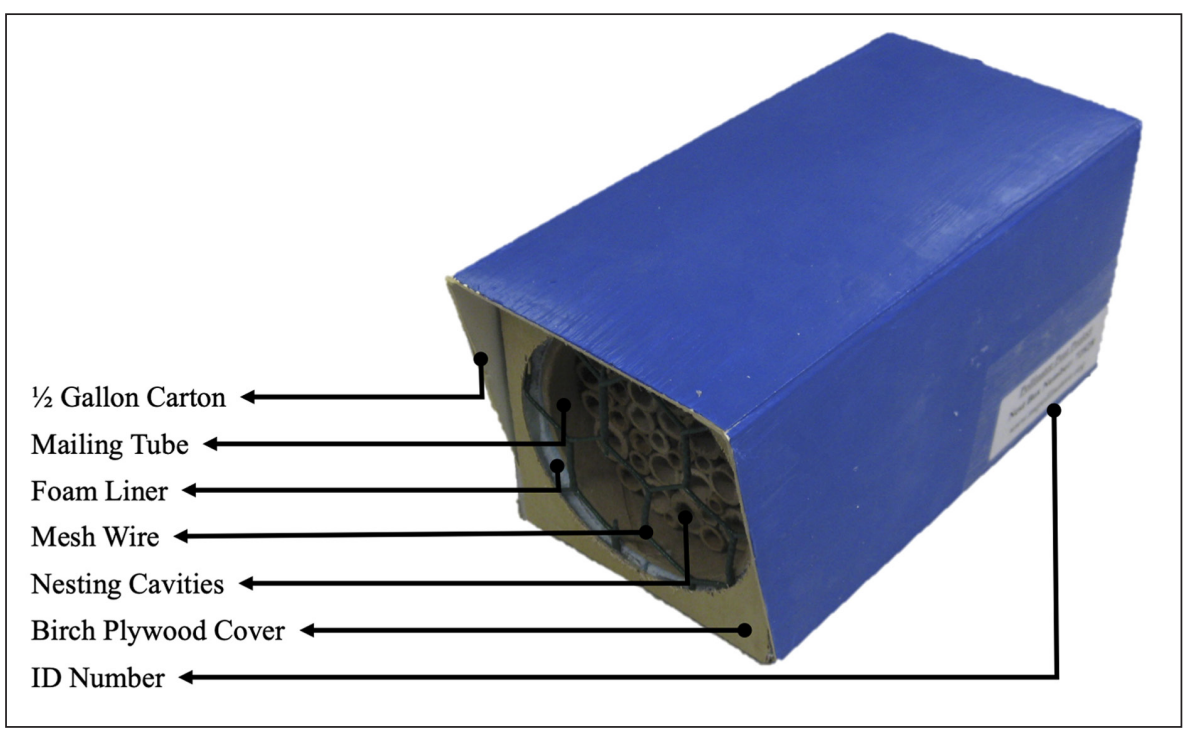

Figure 2: Nest box given to citizen scientists to record habitat preferences of wild bee pollinators in urban gardens. 
Table 1: Statements used in Likert-scale questionnaire of trainees. Volunteers were asked to respond to each statement on a 1 to 5 scale.

\begin{tabular}{|c|c|}
\hline Statement & Assessment Category \\
\hline Prior to this course, my knowledge of how to properly identify floral visitors was limited & Learning \\
\hline After taking this course, I am more confident that my insect identifications are correct & Learning \\
\hline I came to this course to learn more about native bee identification & Reason for attending \\
\hline I came to this course to become part of a citizen science program & Reason for attending \\
\hline The expectations of course participants were clear and concise & Expectations \\
\hline The course was well organized & Structure \\
\hline I intend to submit my out-of-class observations of native bees on the website & Intent \\
\hline
\end{tabular}

\section{Website and volunteer educational attainment}

Trainees were required to register on our website to submit data for both projects. However, website registration was open to all website visitors, allowing us to evaluate both website visitors in general and individuals who visited our website after receiving a training. We queried all registrants to determine their educational level attained (no college education, undergraduate, M.S., or Ph.D.) and previous experience with pollinator identification (took training, self-taught, none, or taught elsewhere). These data were assigned to each registrant's account. Registrants could also submit biographical information and choose a profile picture. Citizen scientists had to sign into their account to submit data, allowing us to correlate submissions for each project with the volunteer's educational level of attainment and prior experience with pollinator identification. We also were able to compare the number of unique project contributors to the total number of trainees, which allowed us to examine retention.

\section{Data analysis}

We used a Pearson's chi-square test to assess if the educational level of attainments were associated with pollinator identification experience. This compared levels of pollinator identification experience across educational level of attainment in a $4 \times 4$ contingency table (4 levels of experience $\times 4$ levels of educational attainment). We also used a Pearson's chi-square test to assess whether trainee retention rates differed across the trainings using a $2 \times 2$ contingency table ( 2 trainings $\times 2$ levels of data collection [yes, no]). Finally, we used a Pearson's chi-square test to determine if educational level of attainment affected data collection with a 4 $\times 2$ contingency table ( 4 educational backgrounds $\times 2$ trainings). Likert-scale responses from questionnaires were evaluated using Wilcoxon rank sum tests. Level of agreement with each statement was treated as a factor (5 = strongly agree, 4 = agree, 3 = neither agree nor disagree, $2=$ disagree and 1 = strongly disagree), and volunteer responses were compared across the two trainings. We also used Wilcoxon rank sum tests to compare responses to statements within each training to determine the primary motivation for trainees to attend trainings. The study sample size was similar to contemporary pollinator citizen science projects (see Birkin and Goulson 2015; Klienke et al. 2018), and all analyses were performed in R (R Core Team 2017).

\section{Results}

We engaged 128 community members in our two citizen science trainings. Of those, 94 took our training on monitoring plant-bee interactions with photography, and 34 took our training on monitoring cavity-nesting bees. Those who took our trainings submitted data from 40 locations throughout the Seattle, WA, USA metropolitan area. For our project that assessed cavity-nesting bees, eight citizen scientists contributed data from two sites each (16 total locations), 13 citizen scientists contributed data from one location each (13 locations), and two citizen scientists shared a location (1 location) for a total of 30 locations across the 23 data contributors. For the project that assessed plant-bee interactions, two citizen scientists submitted data from three sites (6 locations), while 4 citizen scientists submitted data from one location (4 locations) for a total of 10 locations across 6 contributors. Volunteers self-selected the garden from which to collect data and were encouraged to submit data from multiple locations to increase data collection for the projects (Figure 1). No volunteer submitted data for both projects.

\section{Educational attainment and pollinator identification experience}

The educational attainment of our website registrants was classified into four groups. More than 50\% had an undergraduate education, while 35\% had an M.S. degree. Fewer than $10 \%$ had a Ph.D. or no college education (Figure 3a). Prior experience with bee identification was similarly distributed. Approximately $44 \%$ of registrants had taken our training before registering online $(n=60)$ while $20 \%$ of registrants had either no prior identification experience or were self-taught. Few $(<10 \%)$ received formal education elsewhere (Figure $\mathbf{3 b}$ ). By crossing pollinator identification experience with educational attainment, we found that 30 to $50 \%$ of volunteers from all levels of educational attainment had taken our training before registering online. Approximately 10 to $45 \%$ of volunteers from all educational levels of attainment reported having no previous experience with pollinator identification, 11 to 30\% of volunteers from all educational levels of attainment were self-taught, and 8 to $12 \%$ were taught pollinator identification elsewhere (Figure 3c). However, there was no significant relationship between educational attain- 


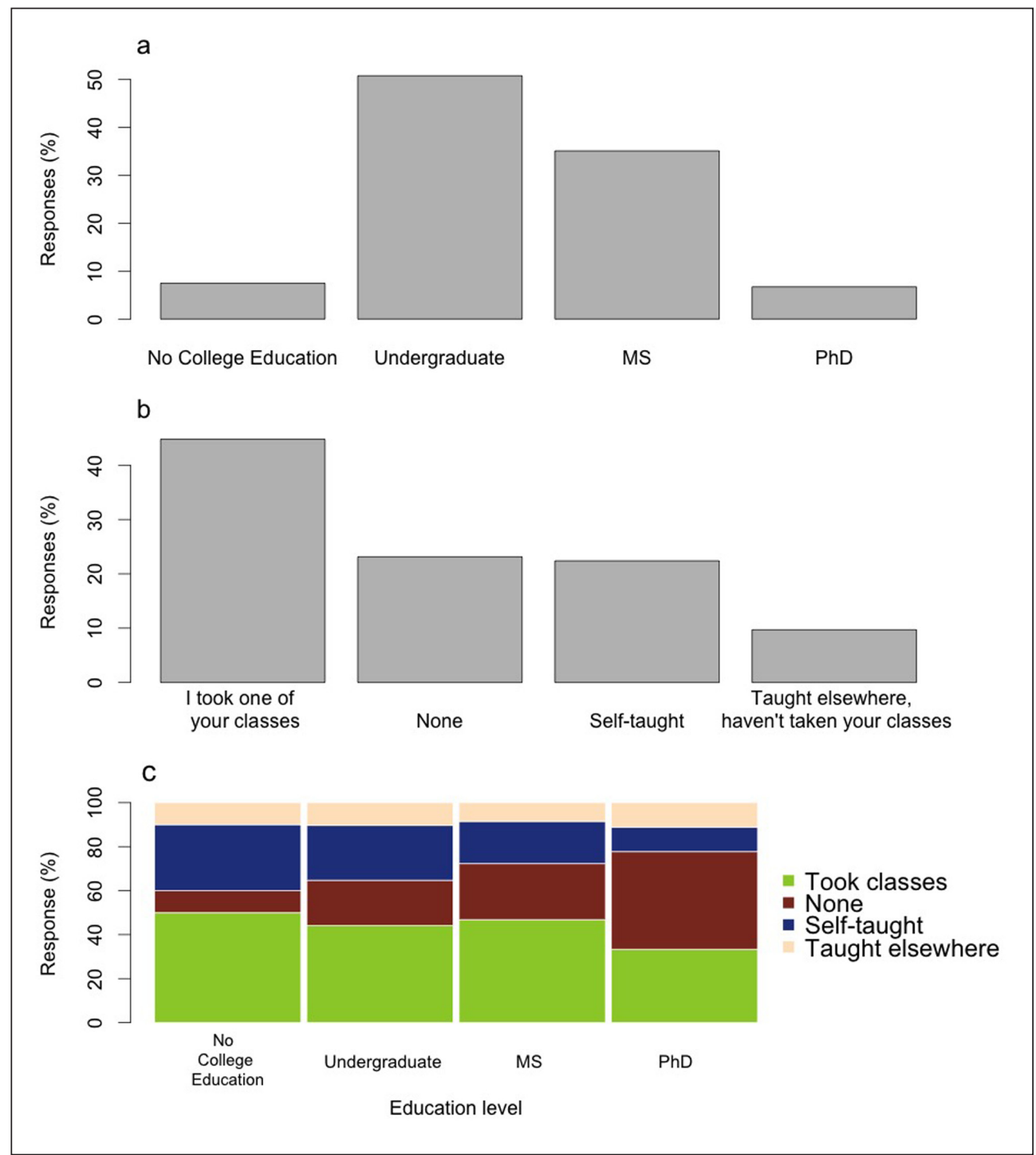

Figure 3: Educational attainment and experience of study volunteers. We queried registrants $(n=128)$ to determine their (a) educational attainment and (b) experience with pollinator identification. (c) The frequency of each attainment level crossed with each experience level.

ment and pollinator identification experience (Pearson's chi-square test; $\left.\chi^{2}=4.50 ; d f=9, P=0.88\right)$.

\section{Retention of volunteers}

Of those who took our trainings, $22 \%$ registered on our website and submitted data. The rate of retention of citizen scientists, from trainings to submitting data, was significantly different among the two projects (Pearson's chisquare test; $\left.\chi^{2}=50.04 ; d f=1 ; P<0.0001\right)$. Twenty-three out of 34 citizen scientists trained in our cavity-nesting bee project (70\%) submitted data, while only 6 out of 94 citizen scientists trained in monitoring plant-bee interactions (6\%) submitted data (Figure 4a). When crossed with data on educational attainment, $80 \%$ of data submitted for the plant-bee interactions project came from those with a M.S. degree, while data submitted for the project that monitors cavity-nesting bee populations was distributed more evenly ( $13 \%$ no college education, $40 \%$ undergraduate, 39\% M.S., 8\% Ph.D.) (Figure 4b). However, educational attainment did not contribute to statistically significant differences in data collection between our citi- zen science projects (Pearson's chi-square test; $\chi^{2}=3.93$; $d f=3 ; P=0.27)$.

\section{Motivations of volunteers and comparisons between trainings}

Trainees who attended our cavity-nesting bee training were more likely than those who took our plant-bee interactions training to agree that: (1) their reason for attending was to become part of a citizen science program, (2) expectations of the training were clear, and (3) they planned to submit data (Table 2). These results reflect the observation that those who took the cavitynesting bee training were more likely to submit data (Figure 4a). Trainees across both projects were similarly: (1) experienced prior to taking our training and (2) confident in their ability to monitor/identify the study organism after the training; volunteers also perceived both trainings as similarly well organized (Table 2 ). However, regardless of the training course, trainees were more likely to have attended to learn more about bees than to collect data (Table 3). 


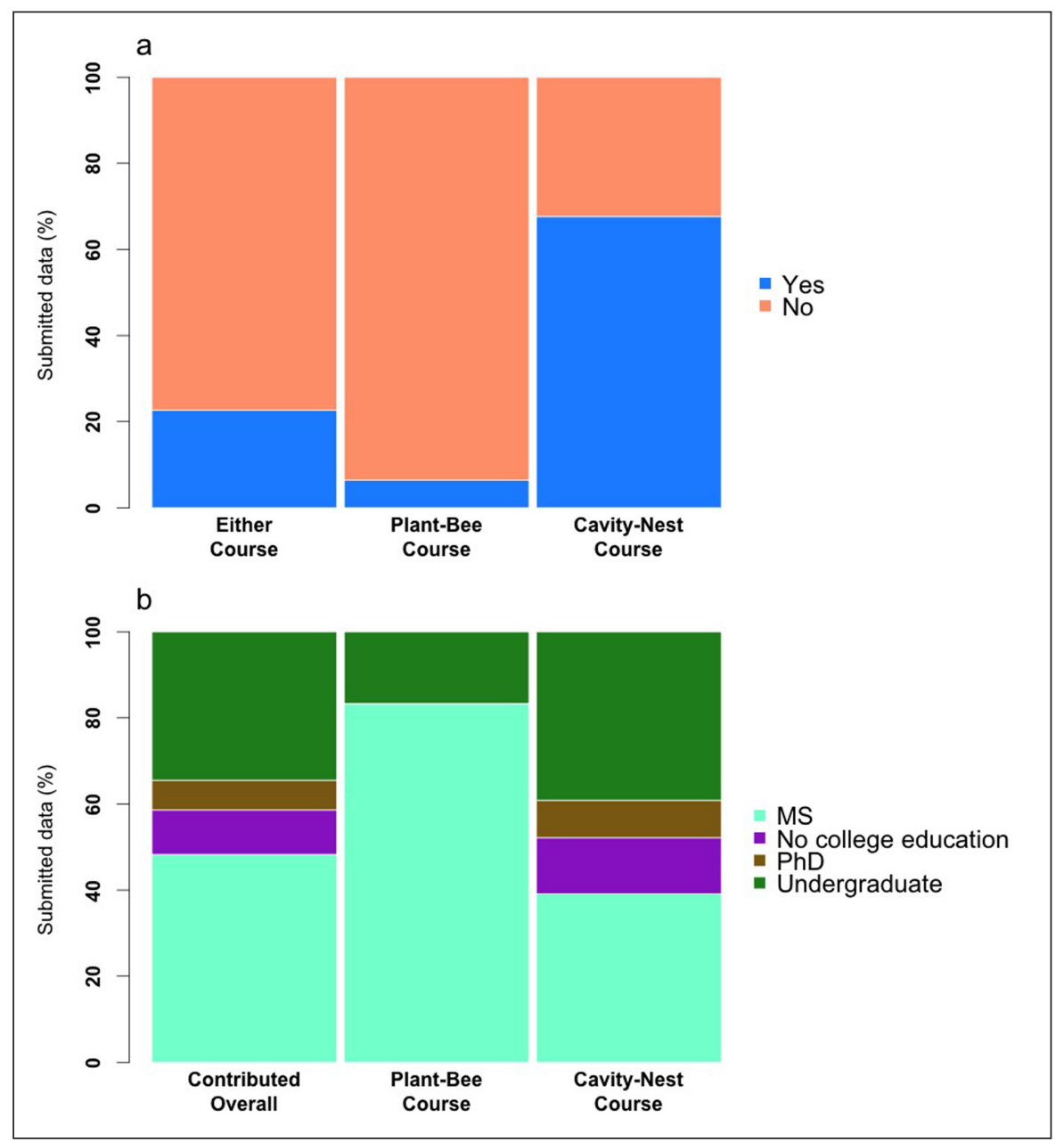

Figure 4: Factors affecting the frequency of data submission. (a) The percentage of trainees, and the percentage that submitted data, for each project. (b) The percentage of trainees across different educational attainments that submitted data across the two projects.

Table 2: Results of Wilcoxon rank sum tests comparing differences of Likert-scale response to each question between the two citizen science trainings. $P$ values below $\alpha=0.05$ (shown with an asterisk) indicate a significant difference in responses across the trainings.

\begin{tabular}{|c|c|c|c|c|c|c|}
\hline Statement & $\begin{array}{l}\text { Assessment } \\
\text { Category }\end{array}$ & Training & Mean & SE & $w$ & $P$ \\
\hline \multirow{2}{*}{$\begin{array}{l}\text { Prior to this course, my knowledge of how to } \\
\text { properly identify floral visitors was limited. }\end{array}$} & \multirow[t]{2}{*}{ Learning } & Cavity-nesting bees & 4.32 & 0.17 & \multirow[t]{2}{*}{1871} & \multirow[t]{2}{*}{0.11} \\
\hline & & Plant-bee interactions & 4.18 & 0.08 & & \\
\hline \multirow{2}{*}{$\begin{array}{l}\text { After taking this course, I am more confident } \\
\text { that my insect identifications are correct. }\end{array}$} & \multirow[t]{2}{*}{ Learning } & Cavity-nesting bees & 4.18 & 0.15 & \multirow[t]{2}{*}{1638} & \multirow[t]{2}{*}{0.58} \\
\hline & & Plant-bee interactions & 4.19 & 0.06 & & \\
\hline \multirow{2}{*}{$\begin{array}{l}\text { I came to this course to learn more about native } \\
\text { bee identification }\end{array}$} & \multirow{2}{*}{$\begin{array}{l}\text { Reason for } \\
\text { attending }\end{array}$} & Cavity-nesting bees & 4.76 & 0.07 & \multirow[t]{2}{*}{1685} & \multirow[t]{2}{*}{0.54} \\
\hline & & Plant-bee interactions & 4.70 & 0.05 & & \\
\hline \multirow{2}{*}{$\begin{array}{l}\text { I came to this course to become part of a citizen } \\
\text { science program }\end{array}$} & \multirow{2}{*}{$\begin{array}{l}\text { Reason for } \\
\text { attending }\end{array}$} & Cavity-nesting bees & 4.24 & 0.15 & \multirow[t]{2}{*}{1946} & \multirow[t]{2}{*}{$0.014^{*}$} \\
\hline & & Plant-bee interactions & 3.76 & 0.11 & & \\
\hline \multirow{2}{*}{$\begin{array}{l}\text { The expectations of course participants were } \\
\text { clear and concise. }\end{array}$} & \multirow[t]{2}{*}{ Expectations } & Cavity-nesting bees & 4.74 & 0.08 & \multirow[t]{2}{*}{1760} & \multirow[t]{2}{*}{$0.018^{*}$} \\
\hline & & Plant-bee interactions & 4.45 & 0.06 & & \\
\hline \multirow[t]{2}{*}{ The course was well organized. } & \multirow[t]{2}{*}{ Structure } & Cavity-nesting bees & 4.68 & 0.08 & \multirow[t]{2}{*}{1670} & \multirow[t]{2}{*}{0.56} \\
\hline & & Plant-bee interactions & 4.61 & 0.05 & & \\
\hline \multirow{2}{*}{$\begin{array}{l}\text { I intend to submit my out-of-class observations } \\
\text { of native bees on the website. }\end{array}$} & \multirow[t]{2}{*}{ Intent } & Cavity-nesting bees & 4.82 & 0.08 & \multirow[t]{2}{*}{2224} & \multirow[t]{2}{*}{$<0.0001^{*}$} \\
\hline & & Plant-bee interactions & 4.22 & 0.09 & & \\
\hline
\end{tabular}


Table 3: Results of Wilcoxon rank sum tests comparing whether volunteers in each training were primarily motivated by educational goals or to become part of a citizen science project. $P$ values below $\alpha=0.05$ (shown with an asterisk) indicate a significant difference between the two possible motivations for each particular training.

\begin{tabular}{llcccc} 
Training & Statement & Mean & SE & $\boldsymbol{W}$ & $\boldsymbol{P}$ \\
\hline $\begin{array}{l}\text { Monitoring plant-bee } \\
\text { interactions }\end{array}$ & $\begin{array}{l}\text { I came to this course to learn more about } \\
\text { native bee identification }\end{array}$ & 4.70 & 0.05 & 6534 & $<0.0001^{*}$ \\
& $\begin{array}{l}\text { I came to this course to become part of a } \\
\text { citizen science program }\end{array}$ & 3.76 & 0.11 & & \\
$\begin{array}{l}\text { Assessing cavity- } \\
\text { nesting bees }\end{array}$ & $\begin{array}{l}\text { I came to this course to learn more about } \\
\text { native bee identification }\end{array}$ & 4.76 & 0.07 & 776 & $0.0049^{*}$ \\
& $\begin{array}{l}\text { I came to this course to become part of a } \\
\text { citizen science program }\end{array}$ & 4.24 & 0.15 & &
\end{tabular}

\section{Discussion}

Many citizen science projects have an overarching goal of conserving wild and managed bee pollinators (Ullman et al. 2010; Potter and LeBuhn 2015; Bloom and Crowder 2016; LeBuhn et al. 2016; Le Féon et al. 2016; van der Wal et al. 2016 Domroese and Johnson 2017; Pocock et al. 2018). However, the factors that affect data collection in pollinator citizen science projects have rarely been studied (but see van der Wal et al. 2016; Domroese and Johnson 2017; Klienke et al. 2018), hindering the development of projects that could promote global pollinator populations. We show that regardless of project methods, volunteers were attracted to our citizen scientist trainings mainly to learn more about pollinators, rather than to assist with data collection on pollinators. This indicates that pollinator projects may need to account for volunteers who are mainly interested in learning, rather than data collection, when assessing the number of volunteers needed to meet the data collection goal of the researcher. We also found that data collection for pollinator projects is project dependent, indicating that the methods of a project have a strong effect on the potential for a project to support pollinator conservation. Evaluation of volunteers indicated that the level of educational attainment of the volunteer did not influence data collection, suggesting that pollinator researchers can likely leverage volunteers from an array of educational attainments to assist with data collection.

Our project that used photography to monitor plantbee interactions was far less likely to receive data submissions than the one that monitored cavity-nesting bees with nest boxes. Other studies have found that pollinator projects that require the volunteers to complete multiple challenging steps suffer from low rates of data collection (Birkin and Goulson 2015; Klienke et al. 2018). For example, Klienke et al. (2018) assessed effects of bees on crop pollination using citizen scientists. Although $76 \%$ of participants in their trainings volunteered to collect data, only $14 \%$ of participants did so. Surveys showed that the complex methods, which involved growing plants, observing pollination, and measuring seed set, were factors that reduced data submissions by volunteers (Klienke et al. 2018). Similarly, only $6 \%$ of individuals trained in our plant-bee interactions project submitted data. This project involved the photography of pollinators, which is known to be challenging for volunteers (Ullman et al. 2010). Conversely, our cavity-nesting bee project, which involved the use of nest boxes that naturally attracted cavity-nesting bees (Bloom et al. 2017), had 70\% of volunteers submit data. Our training questionnaire effectively predicted the likelihood of data submission for volunteers in each training and showed that if training participants perceive methods as too difficult (e.g., photographing pollinators), this may affect their responses. Our results indicate that pre-surveys could determine participation before data collection starts, aiding researchers to estimate the number of trainees needed to reach data collection goals. Moreover, data collected by nest boxes are also less likely to be skewed by the observer because they naturally attract bees (Bloom et al. 2017). Observational bias can skew data collection in citizen science projects (Wilson et al. 2017; Callaghan et al. 2019; Kelling et al. 2019), where volunteers have been found to overestimate species richness (Gardiner et al. 2012). Our projects indicate that recording plant-bee interactions may be too difficult for most volunteers, and researchers may collect more, higher quality data using nest boxes or other methods such as passive traps (Pocock et al. 2018).

While project methods can contribute to the likelihood of data collection, our study also revealed that volunteers were more likely to attend both of our trainings to learn more about pollinators rather than to participate in citizen science. This occurred despite volunteers often stating that training expectations were clear, suggesting that volunteers attended trainings to learn more about pollinators even when data collection was the main goal of our research team. This finding further indicates that the motivations for volunteerism may vary strongly across citizen science projects (Bonney et al. 2009; Sullivan et al. 2009; Dickinson et al. 2012; Wright et al. 2015; Lucrezi et al. 2018), and agrees with contemporary findings that suggest volunteers engage in pollinator citizen science primarily for educational reasons (Domroese and Johnson 2017). Our study therefore adds to a growing body of evidence that pollinator citizen science projects may be serving as an educational resource for individuals interested in the global decline of pollinator populations (Wilson et al. 2017). One factor that may underlie the strong motivation of volunteers in both of our trainings to further their own education is the general lack of educational 
programs available to the public on pollinator conservation. For example, on average only $10.3 \%$ of citizen science registrants from all educational levels of attainment received pollinator education outside of our training. This suggests that a lack of educational resources on pollinators, combined with the intense public interest in pollinator conservation, may be driving volunteers to attend our trainings. Moreover, it confirms that citizen science can play a role not only in data collection but also in educating communities where researchers are collecting data (Bonney et al. 2009; Jordan et al. 2011).

Our results show that the educational level of attainment did not affect the likelihood of data collection, and that pollinator identification experience was similar across the levels of educational attainment in our volunteer group. This suggests that volunteers with all levels of educational attainment were equally likely to contribute to citizen science. However, while we observed no effect of the level of educational attainment on the propensity to submit data for either of our citizen science projects, both projects did primarily attract individuals with college degrees. Data from the US Census Bureau (2016) show that $32.8 \%$ of individuals in our study region are without a college education, but this demographic represented less than $10 \%$ of our study volunteers. Indeed, our study shows that engaging participants from all levels of educational attainment remains a problem across citizen science projects and should thus be of increased consideration for researchers (Brossard, Lewenstein, and Bonney 2011; Crall et al. 2013; Branchini et al. 2015; Wright et al. 2015; Domroese and Johnson 2017; Roman et al. 2017).

Our study was conducted in Seattle, Washington, where the level of educational attainment is spatially segregated and regions with low educational attainment are historically represented by minority groups (US Census Bureau 2016). Many small-scale farmers and urban gardeners in this region are from immigrant farming communities including Latino, Hmung, East African, and Eastern European farmer-operators (Ostrom and Donovan 2015). To encourage participation from such underrepresented groups, we suggest that researchers engage with community leaders to develop culturally sensitive monitoring guides (e.g., Spanish language translations) and training materials (Pandya 2012; Grasswitz 2019). For example, in Hmung culture, the written language is rarely used and farmers typically learn through storytelling and visual means. Therefore, citizen science training guides would likely need to be developed in video format to reach this underrepresented demographic (Grasswitz 2019).

While our study focused on urban areas, rural regions also often have many pollinator dependent cropping systems (Kremen, Ullman, and Thorp 2011), and natural areas where pollinator populations are in decline (Goulson et al. 2015; Koh et al. 2016). The demographics and level of educational attainment in such rural regions often differs from adjacent urban areas (USDA 2017), suggesting a unique opportunity for researchers to engage citizen scientists across urban to rural gradients. We suggest that researchers work closely with university extension and government agencies (e.g., the Farm Service) in volunteer recruitment efforts and develop approaches for farmer operators that integrate citizen science into preexisting farming practices (e.g., scouting for pest insects). Indeed, we proposed a scheme whereby researchers work with farmer citizen scientists to enhance data collection on organic farming systems (Bloom and Crowder 2016), however, to our knowledge no such system has been developed (but see Dehnen-Schmutz et al. 2016) and would likely be useful in rural agricultural areas where pollinators may be in decline (Koh et al. 2016).

By understanding the factors that promote the successful retention of citizen scientists, pollinator researchers may be able to optimize data collection efforts. For example, some projects with high ecological value which have many detail-oriented steps may require training more participants to reach data collection goals (Birkin and Goulson 2015; Kleinke et al. 2018). However, citizen science, regardless of the project or volunteer retention, has the potential to fulfill valuable science education needs for everyone who takes the training including those that do not contribute to data collection, and will not likely be hindered by including individuals of different educational levels of attainment. Researchers should leverage the predictive power of questionnaires prior to initiating projects (see Phillips et al. 2014) to determine the likelihood of data submission given that the loss of approximately $94 \%$ of trainees, as we observed in our plant-bee project, would be unacceptable for many researchers to reach data collection goals. Moreover, data submission rates will lead to projects that fail to collect the abundance of data needed to meet the goals of researchers. Thus, it is important to be realistic and conservative when estimating data submission rates after training, especially for more difficult projects. More broadly, our results suggest that the future of pollinator citizen science depends on developing projects that promote data collection through the use of simple and highly robust data collection techniques and attractive educational components.

\section{Ethics and Consent}

The Likert-scale questionnaire used in this study was approved by the Internal Review Board of Washington State University, Pullman, WA, USA.

\section{Acknowledgements}

We thank the 128 volunteers who took our trainings. We thank our partners, Tilth Alliance, 21 Acres, and Seattle Parks and Recreation. We also thank O. Atis, T. Hargrave, S. Siehl, and K. Sahl for their help administering trainings and for feedback during project development.

\section{Funding Information}

This project was supported by a NSF Graduate Research Fellowship to EB (Grant 124006-001), USDA Organic Transitions Grant to DC and EB (Grant 2014-51106-22096), USDA Fellowship to EB (Grant 2017-67011-26025), and Western SARE to EB (Grants GW15-022).

\section{Competing Interests}

The authors have no competing interests to declare. 


\section{Author Contributions}

EB and DC conceived the study. EB carried out the trainings with assistance from the project team. EB conducted the data analysis. EB and DC wrote the manuscript.

\section{References}

Barro, RJ and Lee, JW. 2013. A new data set of educational attainment in the world, 1950-2010. Journal of Development Economics, 104(C): 184-198. DOI: https://doi.org/10.1016/j.jdeveco.2012.10.001

Birkin, L and Goulson, D. 2015. Using citizen science to monitor pollination services. Ecological Entomology, 40(S1): 3-11. DOI: https://doi.org/10.1111/ een. 12227

Bloom, EH and Crowder, DW. 2016. Biological control and pollination services on organic farms. In: Horowitz, AR and Ishaaya, I (eds.), Advances in insect control and resistance management, 27-46. Gewerbestrasse, Switzerland: Springer International Publishing AG. DOI: https://doi.org/10.1007/978-3-319-31800-4_3

Bloom, EH, Northfield, TD and Crowder, DW. 2019. A novel application of the Price equation reveals that landscape diversity promotes the response of bees to regionally rare plant species. Ecology Letters. In press. DOI: https://doi.org/10.1111/ele.13406

Bloom, EH, Olsson, RL and Crowder, DW. 2017. A citizen science guide to wild bees and floral visitors in western Washington. Pullman, Washington, USA: Washington State University.

Bloom, EH, Olsson, RL, Wine, HW, Schaeffer, RN and Crowder, WC. 2017. An introduction to cavity-nesting bees in the Puget Sound region. Pullman, Washington, USA: Washington State University.

Bonney, R, Cooper, CB, Dickinson, J, Kelling, S, Phillips, T, Rosenbery, KV and Shirk, J. 2009. Citizen science: a developing tool for expanding science knowledge and scientific literacy. Bioscience, 59(11): 977-984. DOI: https://doi.org/10.1525/bio.2009.59.11.9

Branchini, S, Meschini, M, Covi, C, Piccinetti, C, Zaccanti, F and Goffredo, S. 2015. Participating in a citizen science monitoring program: implications for environmental education. Plos One, 10(7): e0131812. DOI: https://doi.org/10.1371/journal. pone. 0131812

Brossard, D, Lewenstein, B and Bonney, R. 2011. Scientific knowledge and attitude change: The impact of a citizen science project. International Journal of Science Education, 27(9): 1099-1121. DOI: https://doi. org/10.1080/09500690500069483

Callaghan, CT, Rowley, JJL, Cornwell, WK, Poore, AGB, and Major, RE. 2019. Improving big citizen science data: moving beyond haphazard sampling. Plos Biology, 17(6): e3000357. DOI: https://doi.org/10.1371/ journal.pbio.3000357

Crall, AW, Jordan, R, Holfelder, K, Newman, GJ, Graham, J and Waller, DM. 2013. The impacts of an invasive species citizen science training program on participant attitudes, behavior and science literacy. Public Understanding of Science, 22(6): 745-764. DOI: https://doi.org/10.1177/0963662511434894
Dehnen-Schmutz, K, Foster, GL, Owen, L and Persello, S. 2016. Exploring the role of smartphone technology for citizen science in agriculture. Agriculture for Sustainable Development, 36: 25. DOI: https://doi. org/10.1007/s13593-016-0359-9

Dickenson, JL, Shirk, J, Bonter, D, Bonney, R, Crain, RL, Martin, J, Phillips, T and Purcell, K. 2012. The current state of citizen science as a tool for ecological research and public engagement. Frontiers in Ecology and the Environment, 10(6): 291-297. DOI: https://doi. org/10.1890/110236

Domroese, MC and Johnson, EA. 2017. Why watch bees? Motivations of citizen science volunteers in the Great Pollinator Project. Biological Conservation, 208(2017): 40-47. DOI: https://doi.org/10.1016/j.biocon.2016.08.020

Druschke, CG and Seltzer, CE. 2013. Failures of engagement: lessons learned from a citizen science pilot study. Applied Environmental Education \& Communication, 11(3-4): 178-188. DOI: https://doi.org/10.1080 /1533015X.2012.777224

Gardiner, MM, Allee, LL, Brown, PMJ, Losey, JE, Roy, HE and Smyth, RR. 2012. Lessons from lady beetles: accuracy of monitoring data from US and UK citizen-science programs. Frontiers in Ecology and the Environment, 10(9): 471-476. DOI: https://doi.org/10.1890/110185

Goulson, D, Nicholls, E, Botìas, C and Rotheray, EL. 2015. Bee declines driven by combined stress from parasites, pesticides, and lack of flowers. Science, 347(6229): 1255957. DOI: https://doi.org/10.1126/ science. 1255957

Graham, JR, Tan, Q, Jones, LC and Ellis, JD. 2014. Native buzz: citizen scientists creating nesting habitat for solitary bees and wasps. Florida Scientist, 77(4): 204-218.

Grasswitz, T. 2019. Integrated pest management (IPM) for small-scale farmers in developed economies: challenges and opportunities. Insects, 10(6): 179. DOI: https://doi.org/10.3390/insects 10060179

Jamieson, S. 2004. Likert scales: how to (ab)use them. Medical Education, 38(12): 1217-1218. DOI: https:// doi.org/10.1111/j.1365-2929.2004.02012.x

Jordan, RC, Gray, SA, Howe, DV, Brooks, WR and Ehrenfeld, JG. 2011. Knowledge gain and behavioral change in citizen science programs. Conservation Practice and Policy, 25(6): 1148-1154. DOI: https://doi. org/10.1111/j.1523-1739.2011.01745.x

Kaartinen, R, Hardwick, B and Roslin, T. 2013. Using citizen scientists to measure an ecosystem service nationwide. Ecology, 94(11): 2645-2652. DOI: https:// doi.org/10.1890/12-1165.1

Kelling, S, Johnston, A, Bonn, A, Fink, D, RuizGutierrez, V, Bonney, R, Fernandez, M, Hochachka, WM, Julliard, R, Kraemer, $\mathbf{R}$ and Guralnick, $\mathbf{R}$. 2019. Using semistructured surveys to improve citizen science data for monitoring biodiversity. Bioscience, 69(3): 170-179. DOI: https://doi.org/10.1093/biosci/ biz010

Klienke, B, Prajzner, S, Gordon, C, Hoekstra, N, Kautz, A and Gardiner, M. 2018. Identifying barriers to 
citizen scientist retention when measuring pollination services. Citizen Science: Theory and Practice, 3(1): 1-10. DOI: https://doi.org/10.5334/cstp.99

Koh, I, Lonsdorf, EV, Williams, NM, Brittain, C, Isaacs, R, Gibbs, J and Ricketts, T. 2016. Modeling the status, trends, and impacts of wild bee abundance in the United States. Proceedings of the National Academy of Sciences of the USA, 113(1): 14-145. DOI: https://doi. org/10.1073/pnas.1517685113

Kremen, C, Ullman, KS and Thorp, RW. 2011. Evaluating the quality of citizen-scientist data on pollinator communities. Conservation Biology, 25(3): 607-617. DOI: https://doi.org/10.1111/j.1523-1739.2011.01657.x

LeBuhn, G, Droege, S, Connor, E, Gemmill-Herren, B and Azzu, N. 2016. Protocol to detect and monitor pollinator communities: guidance for practitioners. Rome: FAO.

Le Féon, V, Henry, M, Guilbaud, L, Coiffait-Gombault, C, Dufrêne, E, Kolodziejczyk, E, Kuhlmann, M, Requier, $\mathbf{F}$ and Vaissière, BE. 2016. An expertassisted citizen science program involving agricultural high schools provides national patterns on bee species assemblages. Journal of Insect Conservation, 20(4): 905-918. DOI: https://doi.org/10.1007/s10841-0169927-1

Likert, R. 1932. A technique for the measurement of attitudes. Archives of Psychology, 22: 5-55.

Lucrezi, S, Milanese, M, Palma, M and Cerrano, C. 2018. Stirring the strategic direction of scuba diving marine citizen science: a survey of active and potential participants. Plos One, 13(8): e0202484. DOI: https:// doi.org/10.1371/journal.pone.0202484

Mason, L and Arathi, HS. 2019. Assessing the efficacy of citizen scientists monitoring native bees in urban areas. Global Ecology and Conservation, 17: e005612. DOI: https://doi.org/10.1016/j.gecco.2019.e00561

Ostrom, M and Donovan, C. 2015. Profile of small farms in Washington State. Pullman, Washington, USA: Washington State University.

Pandya, RE. 2012. A framework for engaging diverse communities in citizen science in the US. Frontiers in Ecology and the Environment, 10(6): 314-317. DOI: https:// doi.org/10.1890/120007

Phillips, T, Ferguson, M, Minarchek, M, Porticella, N and Bonney, R. 2014. User's guide for evaluating learning outcomes in citizen science. Ithaca, NY, USA: Cornell Lab of Ornithology.

Pocock, MJO, Chandler, M, Bonney, R, Thornhill, I, Albin, A, August, T, Bachman, S, Brown, PMJ, Cunha, DGF, Grez, A, Jackson, C, Peters, M, Rabarijaon, NR, Roy, HE, Zaviezo, T and Danielsen, F. 2018. A vision for global biodiversity monitoring with citizen science. Advances in Ecological Research, 59: 169-223. DOI: https://doi.org/10.1016/bs.aecr.2018.06.003

Pollinator Health Task Force. 2015. Pollinator research action plan. Washington, DC, USA: The White House.

Potter, A and LeBuhn, G. 2015. Pollination service to urban agriculture in San Francisco. Urban Ecosys- tems, 18(3): 885-893. DOI: https://doi.org/10.1007/ s11252-015-0435-y

R Core Team. 2017. R: A language and environment for statistical computing. Vienna, Austria: R Foundation for Statistical Computing. URL: https://www.R-project.org/.

Roman, L, Scharenbroch, BC, Östberg, JPA, Mueller, LE, Henning, JG, Koeser, AK, Sanders, JR, Betz, DR and Jordan, RC. 2017. Data quality in citizen science urban tree inventories. 22: 124-135. DOI: https://doi. org/10.1016/j.ufug.2017.02.001

Roy, HE, Baxter, E, Saunder, A and Pocock, MJO. 2016. Focal plant observations as a standardized method for pollinator monitoring: opportunities and limitations for mass participation citizen science. PLOS ONE, 11: e0150794. DOI: https://doi.org/10.1371/journal. pone.0150794

Sauermann, H and Franzoni, C. 2015. Crowd science user contribution patterns and their implications. PNAS, 112(3):679-684. DOI: https://doi.org/10.1073/ pnas. 1408907112

Sullivan, BL, Christopher, LW, Iliff, MJ, Bonney, RE, Fink, D and Kelling, S. 2009. eBird: A citizen-based bird observation network in the biological sciences. Biological Conservation, 142(10): 2282-2292. DOI: https://doi.org/10.1016/j.biocon.2009.05.006

Turrini, T, Dörler, D, Richter, A, Heigl, F and Bonn, A. 2018. The threefold potential of environmental citizen science - Generating knowledge, creating learning opportunities and enabling civic participation. Biological Conservation, 225(2018): 176-186. DOI: https:// doi.org/10.1016/j.biocon.2018.03.024

Ullman, KM, Vaughan, M, Kremen, C, Shih, T and Shepherd, M. 2010. California pollinator project citizen scientist pollinator monitoring guide. Portland, Oregon: The Xerces Society for Invertebrate Conservation.

U.S. Census Bureau. 2016. 2012-2016 American community survey 5-year estimates.

USDA. 2017. Rural education at a glance. Economic Information Bulletin, 171.

van der Wal, R, Sharma, N, Mellish, C, Robinson, R, and Siddharthan, A. 2016. The role of automated feedback in training and retaining biological recorders for citizen science. Conservation Biology, 30(3): 550-561. DOI: https://doi.org/10.1111/ cobi.12705

Wilson, JS, Forister, ML and Carril, OM. 2017. Interest exceeds understanding in public support of bee conservation. Frontiers in Ecology and the Environment, 15(8): 460-466. DOI: https://doi.org/10.1002/ fee. 1531

Wright, DR, Underhill, LG, Keene, M and Knight, AT. 2015. Understanding the motivations and satisfactions of volunteers to improve the effectiveness of citizen science programs. Society \& Natural Resources, 28(9): 1013-1029. DOI: https://doi.org/10.1080/08941920. 2015.1054976 
How to cite this article: Bloom, EH and Crowder, DW. 2020. Promoting Data Collection in Pollinator Citizen Science Projects. Citizen Science: Theory and Practice, 5(1): 3, pp. 1-12. DOl: https://doi.org/10.5334/cstp.217

Submitted: 07 November 2018 Accepted: 27 November 2019 Published: 20 January 2020

Copyright: $\odot 2020$ The Author(s). This is an open-access article distributed under the terms of the Creative Commons Attribution 4.0 International License (CC-BY 4.0), which permits unrestricted use, distribution, and reproduction in any medium, provided the original author and source are credited. See https://creativecommons.org/licenses/by/4.0/.

]u[ Citizen Science: Theory and Practice is a peer-reviewed open access journal published by Ubiquity Press. 